\title{
Early life stress and hippocampal neurogenesis in the neonate: sexual dimorphism, long term consequences and possible mediators
}

\author{
Naima Lajud and Luz Torner* \\ División de Neurociencias, Centro de Investigación Biomédica de Michoacán, Instituto Mexicano del Seguro Social, Morelia, Mexico
}

\author{
Edited by: \\ Xiao-Dong Wang, Zhejiang University, \\ China \\ Reviewed by: \\ Harmen J. Krugers, Universiteit van \\ Amsterdam, Netherlands \\ Muriel Koehl, Institut National de la \\ Santé et de la Recherche Médicale, \\ France

\section{*Correspondence:} \\ Luz Torner, División de Neurociencias, \\ Centro de Investigación Biomédica de \\ Michoacán, Instituto Mexicano del \\ Seguro Social, Camino de la Arboleda \\ 300, Ex Hacienda de San José la \\ Huerta, Morelia, 58341 Michoacán, \\ Mexico \\ e-mail: luz_torner@yahoo.com
}

Adverse early life experience decreases adult hippocampal neurogenesis and results in increased vulnerability to neuropsychiatric disorders. Despite that the effects of postnatal stress on neurogenesis have been widely studied in adult individuals, few efforts have been done to evaluate its immediate effects on the developing hippocampus. Moreover, it is not clear whether postnatal stress causes a differential impact in hippocampus development in male and female neonates that could be related to emotional deficits in adulthood. It has been proposed that the long term effects of early stress exposure rise from a persistent HPA axis activation during sensitive time windows; nevertheless the exact mechanisms and mediators remain unknown. Here, we summarize the immediate and late effects of early life stress on hippocampal neurogenesis in male and female rat pups, compare its later consequences in emotionality, and highlight some relevant mediator peptides that could be potentially involved in programming.

Keywords: hippocampus, stress, neuroplasticity, stress mediators, gender differences

\section{INTRODUCTION}

Early life stress influences behavioral and physiological functions in the individuals, and results in long term changes in neuronal function increasing the vulnerability to suffer a psychiatric diseases (Felitti et al., 1998; Heim and Nemeroff, 2001). The hippocampus is involved in cognitive functions, and is an important regulator of emotional responses to stress, as it is one of the brain structures involved in glucocorticoid (GC) mediated HPA axis negative feedback. It is also one of the two niches where new neurons are actively produced throughout life. Early exposure to adverse experiences induces permanent changes in brain development that include alterations of the hippocampal formation and a reduced or altered neural plasticity. Since the hippocampus is especially vulnerable to GC induced toxicity, it has been hypothesized that stress exposure during sensitive time windows causes alterations on hippocampal development leading to a vicious circle, which perpetuates and exacerbates the long term consequences of early life stress (Sapolsky and Meaney, 1986). However, it is not totally clarified whether changes in neurogenesis originate as a result of many alterations in the hippocampal structure along the time line, or are an immediate consequence of stress exposure. Also, it is unclear whether neural plasticity is equally affected in male and female subjects at early ages. In the present work we will discuss the effects of early life stress on hippocampal developmental neurogenesis and will include a short summary of some possible mediators of stressful effects.

\section{THE STRESS RESPONSE}

Stress involves the activation of the autonomic nervous and neuroendocrine systems to release a cascade of neurotransmitters, hormones, and other chemical messengers that induce behavioral and metabolic changes in the organism. A fast response is conveyed by the autonomic nervous system. A delayed response activates the hypothalamic paraventricular nucleus (PVN) to release corticotropin releasing hormone $(\mathrm{CRH})$ to the portal vasculature of the anterior pituitary gland; $\mathrm{CRH}$ stimulates the release of adrenocorticotropin hormone (ACTH) which triggers the release of GCs from the adrenal cortex. GCs exert a negative feedback regulating HPA axis activity via its own receptors [glucocorticoid receptors (GRs) and mineralocorticoid receptors (MRs)] in anterior pituitary, hypothalamus (de Kloet et al., 2005a), hippocampus and prefrontal cortex. In adults, the effects of allostatic load dissipate following the removal of the stressor; however, the effects of early life stress are persistent far beyond the period of stress exposure.

\section{ANIMAL MODELS OF EARLY LIFE ADVERSITY}

Animal models that reproduce many of the features of chronic stress or adverse experiences during early life include prenatal stress (PS) exposure (Lemaire et al., 2000), acute maternal deprivation (MD) procedures (de Kloet et al., 2005b), chronic or periodic maternal separation (MS) models (Sanchez et al., 2001; Huot et al., 2002; Plotsky et al., 2005), chronic early life stress (CES; Ivy et al., 2008), and early weaning of the pups (Kikusui and Mori, 2009). During late pregnancy, maternal GC mediate changes in fetal HPA responsiveness that is already functional. Infant rodents spend their first weeks of life in the maternal nest; hence, interactions of the pups with their mother and littermates are essential for optimal brain development and social skills (Sanchez et al., 2001; Huot et al., 2002). Separation from the dam for prolonged periods $(>2 \mathrm{~h})$ is perceived as a threat by the offspring, and activates 
the neonate's HPA axis, causing elevated basal and/or stressinduced corticosterone levels in the adult (Lajud et al., 2012a). $\mathrm{MD}$ is an acute traumatic event that consists on separating the offspring from the dam for a $24 \mathrm{~h}$ period, and involves both nutritional and sensory (stimulation) factors (Suchecki et al., 1993), while MS is a chronic moderate stressor that involves daily separations from the dam during the first 2 or 3 weeks of life. It has been proposed that adult phenotype induced by MS is programmed by the pup's stressful experience during prolonged MS, rather than by prolonged maternal absence per se (Daskalakis et al., 2014). Variations in the MS model include daily separations of $3 \mathrm{~h}$ (MS180) or more (MS360), once or twice a day, from days 1-14, 2-21, or 15-21, etc. (Nishi et al., 2014). The CESs model, interferes with the mother infant interaction through the induction of a reduced maternal care, due to poor housing conditions (scarce material to build a nest) from PN2 to PN9, and resembles maternal anxiety and neglect (Ivy et al., 2008). These models reproduce many of the consequences observed in humans subjected to adverse early experiences, such as infant maltreatment or abuse, low socio economic status, etc., (Sanchez et al., 2001; Huot et al., 2002; Plotsky et al., 2005), in terms of a chronic exposure to adverse situations. Since effects of PS on neurogenesis have been more studied, we will review the studies on early neurogenesis focusing more on the effects of postnatal stress.

\section{DEVELOPMENT OF THE HIPPOCAMPUS}

The development of the rodent dentate gyrus (DG) can be subdivided into two major phases. First, the granule cells of the outer shell (Figure 1, blue) originate prenatally from the neuroepithelium (NE) located near the fimbria and migrate from the progressively receding secondary dentate matrix to the subpial zone (SPZ; Figure 1, blue). The first dentate migration (dgml) is the source of the earliest generated granule cells that will constitute the outer shell of the granular layer (Altman and Bayer, 1990a,b; Li et al., 2009). During the second postnatal phase (Figure 1, red), the precursor cells build up a new proliferation zone distributed within the hilus, and the early embryonic radial glial scaffold from the ventricular zone (VZ) is replaced by a secondary glial scaffold that traverses the hilus (Figure 1, green). Most radial glial cells, support migrating neurons and serve as precursor cells for both neurogenesis and gliogenesis (Brunne et al., 2013). This tertiary dentate matrix peaks its proliferation rate between PND3 and PND10 and is responsible for the great increase in granule cell population during the neonatal period (Bayer, 1980). The granule cells (Figure 1, red) colonize either the outer shell or the inner core of the granule cell layer (GCL) in a symmetrical manner (Martin et al., 2002), and neurogenesis follows a characteristic dorso - ventral maturation gradient (Schlessinger et al., 1975). During the third and fourth weeks of life, the tertiary dentate matrix disappears and henceforth the neurogenic niche becomes

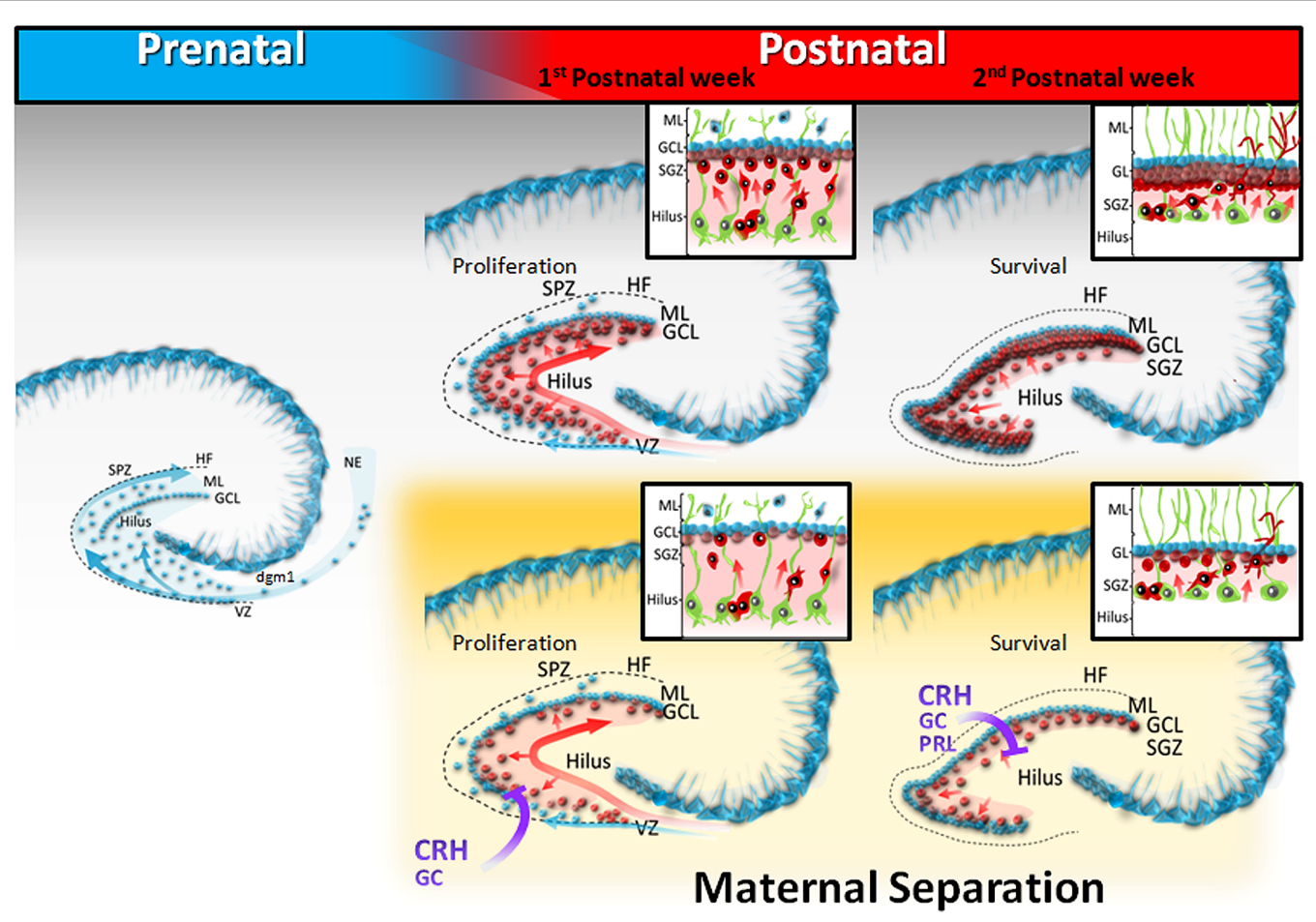

FIGURE 1 | Schematic diagram of dentate gyrus development in postnatally stressed pups. During prenatal development (E17-22), the granule cells of the outer shell (blue) originate from the neuroepithelium (NE), and migrate to the subpial zone (SPZ), or traverse the hilus.

Throughout the first postnatal week, the precursor cells build up a new proliferation zone distributed within the hilus (light red), and granule cells of the GCL inner core migrate, following the arrangement of the secondary radial glial scaffold (green). During the second week of life, the neurogenic niche is confined to the subgranular zone (SGZ). Maternal separation decreases both proliferation and survival of new neurons, generated in the hilar tertiary dentate matrix, probably through stress mediated mechanisms. 
largely confined to the subgranular zone (SGZ; Altman and Bayer, 1990b). This SGZ is the main source of granule cells produced during early life and adulthood. For lifelong neurogenesis to occur, the DG must maintain the appropriate precursor cell niche in the SGZ, which is likely to be dependent on the developmental mechanisms at play during the DG formation. Stress exposure during the first weeks of life may have a significant impact on the maturation of the DG, as it disrupts the organization of the secondary and/or tertiary dentate matrix, altering permanently the structure and function of the hippocampus immediately after stress exposure.

\section{EARLY LIFE STRESS AND HIPPOCAMPAL NEUROGENESIS}

Differences in neurogenesis between male and female pups have been recognized. More new BrdU+ cells were found in the DG of male rat pups compared to females at PN1 and PN4 (Zhang et al., 2008). Control males showed a higher proliferation rate, and increased survival of newborn cells, compared to control females. In addition, a larger granular cell layer volume and more young neurons (DCX) was found in males (Oomen et al., 2009). However, other group reported no differences on neurogenesis rates between male and female pups at PN15 (Lajud et al., 2013).

Early life adverse effects on adult hippocampal neurogenesis have been widely evaluated (Korosi et al., 2012), however the early effects during stress exposure period remain unclear. Immediate effects of stress exposure on hippocampal developmental neurogenesis, were initially addressed by Tanapat et al. (1998) who showed a reduced proliferation in the DG of male rat pups $24 \mathrm{~h}$ after a single stress exposure. MS also decreased the granular cell number in juvenile rats (Oreland et al., 2010). Early weaning in mice at PN15 induced fewer BrdU + cells in the DG of male, but not female mice (Kikusui and Mori, 2009). MS (6 h/day) followed by early weaning (PN15) decreased cell proliferation in the DG of juvenile male rats (Baek etal., 2011, 2012). We showed that MS180 decreased the number and the density of BrdU+ cells in the DG of male pups, at PN15 (Lajud et al., 2012a). In contrast, increased cell proliferation and differentiation in the DG was found in male pups using the CES model (PND2 to PND9; Naninck et al., 2014). Since increased basal corticosterone levels were observed in CES pups (Naninck et al., 2014) but not after MS180 (Lajud et al., 2012a), we cannot exclude the possibility that the etiology of the adverse stimulus could exert differential effects. Maternally deprived pups (24 h PN3), showed decreased cell proliferation but not cell survival at PN21 (Oomen et al., 2009). In opposition to the studies in male pups, there are fewer reports concerning females. The number of BrdU+ cells was unchanged in the DG of female mice in response to early weaning (Kikusui and Mori, 2009). Naninck et al. (2014) showed an increased cell proliferation and differentiation in the DG of female CES pups. Preliminary studies from our group showed a decrease of cell survival in the DG of rat female pups at PN15, after MS180 (Lajud et al., 2012b). MD at PN3 found no changes in cell proliferation or survival in the DG of female pups at PN21, but only a decrease in the number of immature neurons (Oomen et al., 2009; Table 1).

In adults, SGZ neurogenesis has been studied with divergent results. For instance, Mirescu et al. (2004) reported that male adult rats subjected to MS180 exhibited decreased cell proliferation and survival with inadequate responses to stress; while Hulshof et al. (2011) observed that cell proliferation in the DG was decreased in adult MS180 rats but not cell survival. Other studies found that adult MS mice had similar rates of proliferating cells in the DG as control groups, but presented a lower survival rate and differentiation (Leslie et al., 2011). Additionally, male adult mice that were early weaned showed a reduced number of BrdU+ cells in the DG (Kikusui and Mori, 2009). In contrast, several studies found an increase in cell proliferation in adult animals, previously subjected to MS180 (Suri et al., 2013; Feng et al., 2014). In a subset of experiments, adult MS mice ( $8 \mathrm{~h} /$ day) exhibited an enhanced hippocampal neurogenesis in adulthood (Hays et al., 2012). Very few studies are done in adult females. Adult MD females showed reduced granule cell number and density in the DG (Oomen et al., 2010, 2011) or presented no effect. Despite a reduced neurogenesis before puberty (Loi et al., 2014) females subjected to limited nesting showed no effect in adulthood (Naninck et al., 2014). These results suggest that protective factors could take place in the female brain.

In summary, most of the studies show a trend of a decreased proliferation and/or a decreased cell survival in the DG of male and female rodents immediately after stress exposure, which could affect mainly the tertiary dentate matrix neurogenic niche. In adulthood, direction of changes is variable. In males, initial changes are sometimes followed by an increase, or by a permanent decrease in these parameters. In females, it seems that early effects of stress on neurogenesis subside in adulthood. In spite of the variety and direction of the changes that take place in the DG, it is assumed that early life stress induces such alterations to enable the individual to cope with future adversity in life (Bagot et al., 2009).

\section{LONG TERM CONSEOUENCES IN EMOTIONALITY}

Early adversity has been linked to the development of psychiatric illness. A neurogenic hypothesis of depression was formulated, after findings of reduced hippocampal volumes in depressed patients, and the fact that chronic stress decreases hippocampal neurogenesis, and increases the risk to develop depression (Jun et al., 2012). Further, antidepressants were found to enhance hippocampal neurogenesis (Santarelli et al., 2003). However, the correlation of long term behavioral changes with hippocampal neurogenesis changes is still controversial due to several observations that neurogenesis and emotionality are independently regulated (Petrik etal., 2012). Proposals to reconcile the different results have been adressed (Eisch and Petrik, 2012).

Practically all the reports in animal models of long term consequences of early adversity in emotionality use adults. Studies vary, from no effects, to increases in anxiety and/or in depressive like behavior in males (Newport et al., 2002; Daniels et al., 2004; Lee et al., 2007; Lajud et al., 2012a; Girardi et al., 2014; Nishi et al., 2014). In females, results are scarce but point to a lack of effect on contextual fear conditioning (Oomen et al., 2011), or anxiety (screened in the elevated plus maze; Grissom etal., 2012), but increase social anxiety (Tsuda and Ogawa, 2012). Fewer studies report changes in neurogenesis (Table 1) together with effects on 


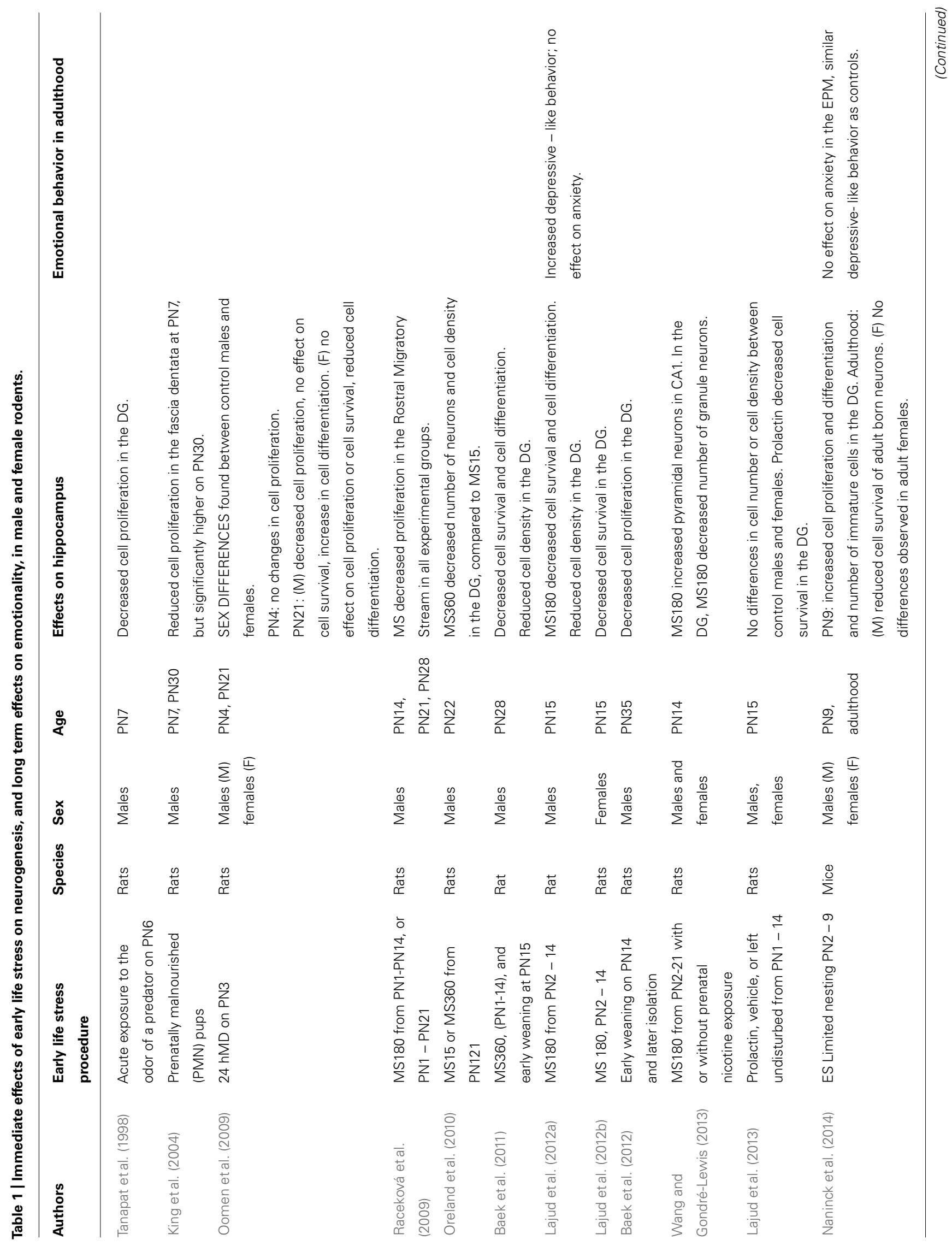




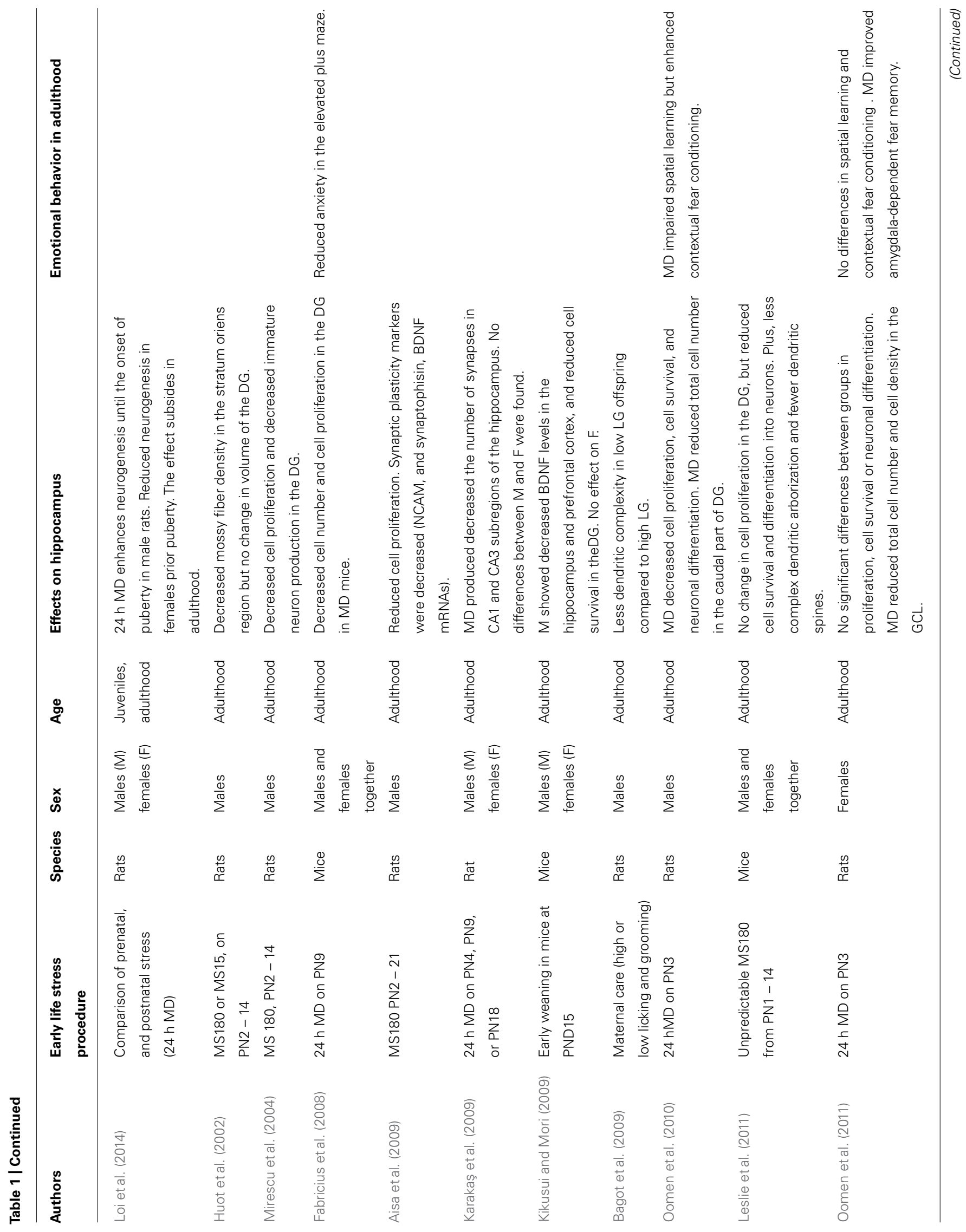




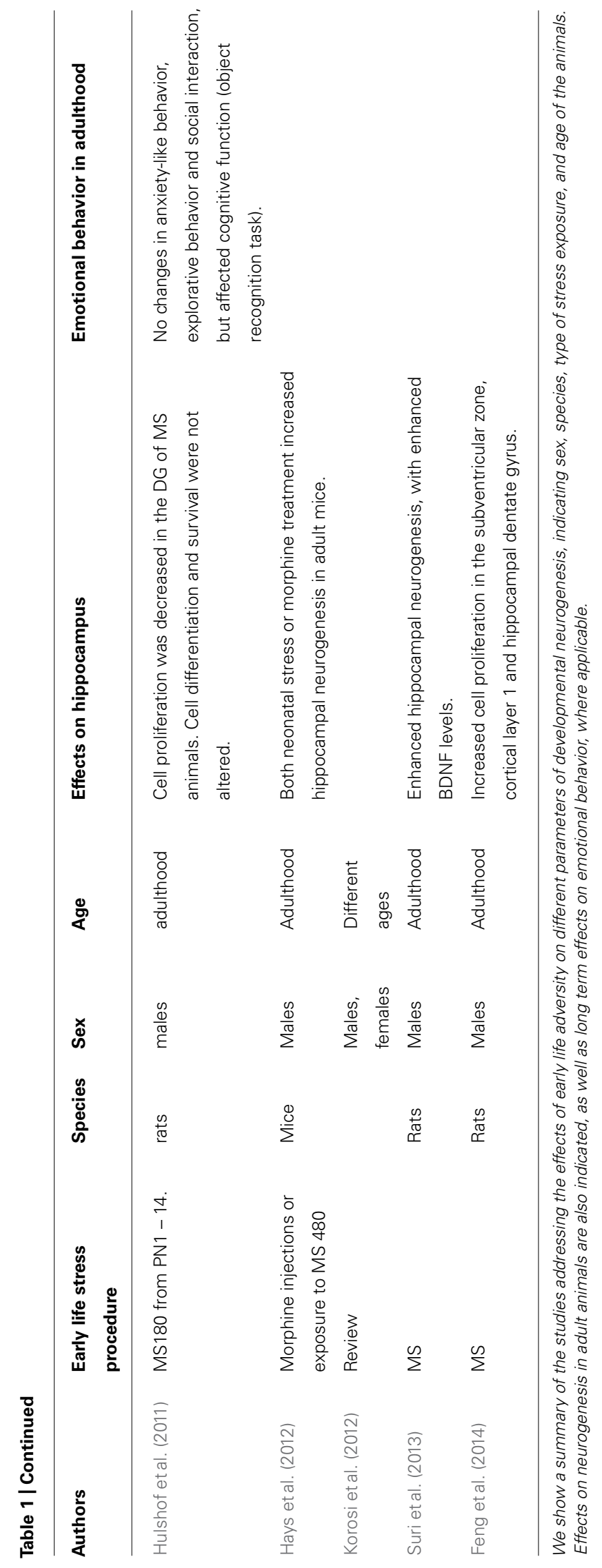


emotionality (Fabricius et al., 2008; Hulshof et al., 2011; Oomen et al., 2011; Lajud et al., 2012a; Naninck et al., 2014). Thus, it seems that in rodents, males are more vulnerable to the effects of early adversity than females.

\section{EARLY LIFE STRESS EFFECTS ON DG DEVELOPMENT AND SOME POSSIBLE MEDIATORS}

We highlight two well-known factors mediating the stress response, and two peptide messengers as potential mediators.

\section{GLUCOCORTICOIDS}

During the first 2 weeks of life, rat pups experience a stress hyporesponsive period (SHRP) due to a markedly reduced adrenocortical response to stress (Sapolsky and Meaney, 1986). GC administration during the first postnatal week decreases granule cell survival, and results in a significant increase in the density of both cell proliferation and death, within the hilus neurogenic niche (Gould et al., 1991). Since then, increased circulating GC levels have been proposed as the main mediators of early life stress effects on hippocampus developmental neurogenesis (Gould and Tanapat, 1999). GCR gene expression is present within the developing brain since early fetal development (Yi and Baram, 1994), and is maximally expressed in the DG between PND10 and 16 (Yi and Baram, 1994); however, other mediators could be involved in the psychopathology of early life stress (Schmidt et al., 2009; Lajud et al., 2012a; Horii-Hayashi et al., 2013; Liao et al., 2014). GCR regulate $\mathrm{CRH}$ gene promoter in the mature brain. In the neonate, second messenger cascades are not yet functional, and GC levels fail to modify CRH expression. Thus, GCR may mediate different functions in the developing neurons, possibly mediated by trophic effects (Yi and Baram, 1994).

\section{CORTICOTROPIN RELEASING HORMONE}

The CRH is considered the link between early life adversity and adult vulnerability (Brunson et al., 2003). CES and MS permanently increase $\mathrm{CRH}$ expression within the hippocampus (Ivy et al., 2010; Wang et al., 2014). Administration of CRH into the brains of infant rats recapitulates some of the long term effects associated with early life stress, even when GC levels are clamped at physiological levels (Brunson et al., 2001; Wang et al., 2012). Blockade of CRHR1 signaling during adulthood significantly attenuated the hippocampal synaptic dysfunction, and memory defects in maternally separated rats (Wang et al., 2014), and treatment blocking CRHR1 from PN10-17 prevented ELS - induced augmentation of hippocampal in middle-aged rats (Ivy et al., 2010). Notably CRHR1, but not GCR, antagonism during the developmental critical period attenuated ES - induced endocrine alterations (Ivy et al., 2010; Liao et al., 2014). Moreover, a specific population of CajalRetzius-like CRH-expressing neurons was characterized during early postnatal hippocampus and these cells seem to contribute to the establishment of hippocampal connectivity (Chen et al., 2001).

\section{PROLACTIN}

Prolactin (PRL) is a pleiotropic hormone promoting a vast array of effects (Freeman et al., 2000). PRL is released in response to stress, regulates hippocampal and SVZ neurogenesis, and modulates anxiety and HPA axis reactivity (Torner et al., 2001, 2009; Shingo et al., 2003). PRL enters the brain through its receptors, located in the choroid plexus cells (Walsh et al., 1987). Daily PRL administration (PN1 to PN14) induced a decrease of DG neurogenesis of PN15 pups (Lajud et al., 2013), and increased depressive - like behavior, in adult male and female rats (Lajud et al., 2013). Studies showed that PRL enhances CRH (Blume et al., 2009) and AVP expression (Donner and Neumann, 2009; Vega et al., 2010). Additionally PRL is cleaved to produce vasoinhibin, which has opposite actions of the native hormone (Zamorano et al., 2014). Thus, PRL could contribute to stress programming.

\section{CITOKINES}

Prenatal maternal infections increase the risk of developing schizophrenia or autism in the offspring (Kofman, 2002; Musaelyan et al., 2014). Immune activation during the perinatal period increases cytokine production, particularly of Interleukin 1 beta (IL-1b) and tumor necrosis factor- $\alpha$, in the hippocampus (Diz-Chaves et al., 2012). Treatment of hippocampal neurospheres with IL-1b showed an antiproliferative, antineurogenic and progliogenic effects (Green et al., 2012). Further, IL-1b reduced the serotonergic differentiation of cultured neurospheres in a dosedependent manner (Zhang et al., 2013). Several studies reported either increases or decreases in cell proliferation or cell survival in the hippocampus offspring depending on the time of exposure and the time of neurogenesis assessment (Musaelyan et al., 2014). Further, mice pups given an immune challenge at PN9, showed reduced cell proliferation, and reduced cell number of neural progenitors at PN41 (Järlestedt et al., 2013). Thus, cytokines play an important role during brain development.

\section{CONCLUDING REMARKS}

Early adversity disrupts the normal concentrations of important neurotransmitters, peptides, hormones, cytokines or their receptors, which are either expressed in the brain or enter the brain compartment during development. These alterations influence the local milieu in the DG, possibly affecting the tertiary dentate matrix and producing a decrease of granular neurons, a decreased cell survival and/or differentiation (Figure 1). Compensatory mechanisms, such as differential expression of neurotrophic factors, might, or not, induce a secondary increase of granular neuron synthesis at adult ages, in both male and female rodents. In any case, the alteration of the development of the structure and compensatory mechanisms induce permanent changes in hippocampal function, which are sometimes accompanied by increased anxiety or depressive-like behavior in males.

\section{AUTHOR CONTRIBUTIONS}

Author Naima Lajud, managed the literature searches, made substantial contributions to the conception or design of the work; wrote a part of the manuscript and revised the work critically, and designed Figure 1. Author Luz Torner made the conception and design of the work, managed the literature searches, made Table 1, wrote a part of the manuscript, revised the work critically, and wrote the final draft. Both authors contributed to and have approved the final manuscript. 


\section{ACKNOWLEDGMENTS}

We thank Mrs. Coral Beedham for language editing services. Funding was provided by grant FIS/IMSS/PROT/GII/922 to LT from Fondo de Investigacion en Salud (FIS), belonging to the Instituto Mexicano del Seguro Social (IMSS). FIS-IMSS had no further role in study design; in the collection, analysis and interpretation of data; in the writing of the report; and in the decision to submit the paper for publication.

\section{REFERENCES}

Aisa, B., Elizalde, N., Tordera, R., Lasheras, B., Del Río, J., and Ramírez, M. J. (2009). Effects of neonatal stress on markers of synaptic plasticity in the hippocampus: implications for spatial memory. Hippocampus 19, 1222-1231. doi: 10.1002/hipo.20586

Altman, J., and Bayer, S. A. (1990a). Migration and distribution of two populations of hippocampal granule cell precursors during the perinatal and postnatal periods. J. Comp. Neurol. 301, 365-381. doi: 10.1002/cne.903010304

Altman, J., and Bayer, S. A. (1990b). Mosaic organization of the hippocampal neuroepithelium and the multiple germinal sources of dentate granule cells. J. Comp. Neurol. 301, 325-342. doi: 10.1002/cne.903010302

Baek, S. B., Bahn, G., Moon, S. J., Lee, J., Kim, K. H., Ko, I. G., et al. (2011). The phosphodiesterase type- 5 inhibitor, tadalafil, improves depressive symptoms, ameliorates memory impairment, as well as suppresses apoptosis and enhances cell proliferation in the hippocampus of maternal-separated rat pups. Neurosci. Lett. 488, 26-30. doi: 10.1016/j.neulet.2010.10.074

Baek, S. S., Jun, T. W., Kim, K. J., Shin, M. S., Kang, S. Y., and Kim, C. J. (2012). Effects of postnatal treadmill exercise on apoptotic neuronal cell death and cell proliferation of maternal-separated rat pups. Brain Dev. 34, 45-56. doi: 10.1016/j.braindev.2011.01.011

Bagot, R. C., van Hasselt, F. N., Champagne, D. L., Meaney, M. J., Krugers, H. J., and Joels M. (2009). Maternal care determines rapid effects of stress mediators on synaptic plasticity in adult rat hippocampal dentate gyrus. Neurobiol. Learn. Mem. 92, 292-300. doi: 10.1016/j.nlm.2009.03.004

Bayer, S. A. (1980). Development of the hippocampal region in the rat. II. Morphogenesis during embryonic and early postnatal life. J. Comp. Neurol. 190, 115-134. doi: 10.1002/cne.901900108

Blume, A., Torner, L., Liu, Y., Subburaju, S., Aguilera, G., and Neumann, I. D. (2009). Prolactin activates mitogen-activated protein kinase signaling and corticotropin releasing hormone transcription in rat hypothalamic neurons. Endocrinology 150 , 1841-1849. doi: 10.1210/en.20081023

Brunne, B., Franco, S., Bouché, E., Herz, J., Howell, B. W., Pahle, J., et al. (2013). Role of the postnatal radial glial scaffold for the development of the dentate gyrus as revealed by reelin signaling mutant mice. Glia 61, 1347-1363. doi: 10.1002/glia.22519

Brunson, K. L., Chen, Y., Avishai-Eliner, S., and Baram, T. Z. (2003). Stress and the developing hippocampus: a double-edged sword? Mol. Neurobiol. 27, 121-136. doi: $10.1385 / \mathrm{MN}: 27: 2: 121$

Brunson, K. L., Eghbal-Ahmadi, M., Bender, R., Chen, Y., and Baram, T. Z. (2001). Long-term, progressive hippocampal cell loss and dysfunction induced by early-life administration of corticotropin-releasing hormone reproduce the effects of early-life stress. Proc. Natl. Acad. Sci. U.S.A. 98, 8856-8861. doi: 10.1073/pnas. 151224898

Chen, Y., Bender, R. A., Frotscher, M., and Baram, T. Z. (2001). Novel and transient populations of corticotropin-releasing hormone-expressing neurons in developing hippocampus suggest unique functional roles: a quantitative spatiotemporal analysis. J. Neurosci. 21, 7171-7181.

Daniels, W. M., Pietersen, C. Y., Carstens, M. E., and Stein, D. J. (2004). Maternal separation in rats leads to anxiety-like behavior and a blunted ACTH response and altered neurotransmitter levels in response to a subsequent stressor. Metab. Brain Dis. 19, 3-14. doi: 10.1023/B:MEBR.0000027412.19664.b3

Daskalakis, N. P., Diamantopoulou, A., Claessens, S. E., Remmers, E., Tjälve, M., Oitzl, M. S., etal. (2014). Early experience of a novel-environment in isolation primes a fearful phenotype characterized by persistent amygdala activation. Psychoneuroendocrinology 39, 39-57. doi: 10.1016/j.psyneuen.2013.09.021

de Kloet, E. R., Joels, M., and Holsboer, F. (2005a). Stress and the brain: from adaptation to disease. Nat. Rev. Neurosci. 6, 463-475. doi: 10.1038/nr n1683 de Kloet, E. R., Sibug, R. M., Helmerhorst, F. M., and Schmidt, M. V. (2005b). Stress, genes and the mechanism of programming the brain for later life. Neurosci. Biobehav. Rev. 29, 271-281. doi: 10.1016/j.neubiorev.2004.10.008

Diz-Chaves, Y., Astiz, M., Bellini, M. J., and Garcia-Segura, L. M. (2012). Prenatal stress increases the expression of proinflammatory cytokines and exacerbates the inflammatory response to LPS in the hippocampal formation of adult male mice. Brain Behav. Immun. 28, 196-206. doi: 10.1016/j.bbi.2012.11.013

Donner, N., and Neumann, I. D. (2009). Effects of chronic intracerebral prolactin on the oxytocinergic and vasopressinergic system of virgin ovariectomized rats. Neuroendocrinology 90, 315-322. doi: 10.1159/000225986

Eisch, A. J., and Petrik, D. (2012). Depression and hippocampal neurogenesis: a road to remission? Science 338, 72-75. doi: 10.1126/science.1222941

Fabricius, K., Wörtwein, G., and Pakkenberg, B. (2008). The impact of maternal separation on adult mouse behaviour and on the total neuron number in the mouse hippocampus. Brain Struct. Funct. 212, 403-416. doi: 10.1007/s00429007-0169-6

Felitti, V. J., Anda, R. F., Nordenberg, D., Williamson, D. F., Spitz, A. M., Edwards, V., et al. (1998). Relationship of childhood abuse and household dysfunction to many of the leading causes of death in adults. The Adverse Childhood Experiences (ACE) study. Am. J. Prev. Med. 14, 245-258. doi: 10.1016/S0749-3797(98) 00017-8

Feng, M., Sheng, G., Li, Z., Wang, J., Ren, K., Jin, X., et al. (2014). Postnatal maternal separation enhances tonic GABA current of cortical layer 5 pyramidal neurons in juvenile rats and promotes genesis of GABAergic neurons in neocortical molecular layer and subventricular zone in adult rats. Behav. Brain Res. 260, 74-82. doi: 10.1016/j.bbr.2013.11.040

Freeman, M. E., Kanyicska, B., Lerant, A., and Nagy, G. (2000). Prolactin: structure, function, and regulation of secretion. Physiol. Rev. 80, 1523-1631.

Girardi, C. E., Zanta, N. C., and Suchecki, D. (2014). Neonatal stress-induced affective changes in adolescent Wistar rats: early signs of schizophrenia-like behavior. Front. Behav. Neurosci. 8:319. doi: 10.3389/fnbeh.2014.00319

Gould, E., and Tanapat, P. (1999). Stress and hippocampal neurogenesis. Biol. Psychiatry 46, 1472-1479. doi: 10.1016/S0006-3223(99)00247-4

Gould, E., Woolley, C. S., Cameron, H. A., Daniels, D. C., and McEwen, B. S. (1991). Adrenal steroids regulate postnatal development of the rat dentate gyrus: II. Effects of glucocorticoids and mineralocorticoids on cell birth. J. Comp. Neurol. 313, 486-493. doi: 10.1002/cne.903130309

Green, H. F., Treacy, E., Keohane, A. K., Sullivan, A. M., O’Keeffe, G. W., and Nolan, Y. M. (2012). A role for interleukin-1 $\beta$ in determining the lineage fate of embryonic rat hippocampal neural precursor cells. Mol. Cell. Neurosci. 49, 311-321. doi: 10.1016/j.mcn.2012.01.001

Grissom, E. M., Hawley, W. R., Bromley-Dulfano, S. S., Marino, S. E., Stathopoulos, N. G., and Dohanich, G. P. (2012). Learning strategy is influenced by trait anxiety and early rearing conditions in prepubertal male, but not prepubertal female rats. Neurobiol. Learn. Mem. 98, 174-181. doi: 10.1016/j.nlm.2012.06.001

Hays, S. L., McPherson, R. J., Juul, S. E., Wallace, G., Schindler, A. G., Chavkin, C., et al. (2012). Long-term effects of neonatal stress on adult conditioned place preference (CPP) and hippocampal neurogenesis. Behav. Brain Res. 227, 7-11. doi: 10.1016/j.bbr.2011.10.033

Heim, C., and Nemeroff, C. B. (2001). The role of childhood trauma in the neurobiology of mood and anxiety disorders: preclinical and clinical studies. Biol. Psychiatry 49, 1023-1039. doi: 10.1016/S0006-3223(01)01157-X

Horii-Hayashi, N., Sasagawa, T., Matsunaga, W., Matsusue, Y., Azuma, C., and Nishi, M. (2013). Developmental changes in desensitisation of c-Fos expression induced by repeated maternal separation in pre-weaned mice. J. Neuroendocrinol. 25, 158-167. doi: 10.1111/j.1365-2826.2012.02377.x

Hulshof, H. J., Novati, A., Sgoifo, A., Luiten, P. G., den Boer, J. A., and Meerlo, P. (2011). Maternal separation decreases adult hippocampal cell proliferation and impairs cognitive performance but has little effect on stress sensitivity and anxiety in adult Wistar rats. Behav. Brain Res. 216, 552-560. doi: 10.1016/j.bbr.2010.08.038

Huot, R. L., Plotsky, P. M., Lenox, R. H., and McNamara, R. K. (2002). Neonatal maternal separation reduces hippocampal mossy fiber density in adult Long Evans rats. Brain Res. 950, 52-63. doi: 10.1016/S0006-8993(02)0 2985-2

Ivy, A. S., Brunson, K. L., Sandman, C., and Baram, T. Z. (2008). Dysfunctional nurturing behavior in rat dams with limited access to nesting material: a clinically relevant model for early-life stress. Neuroscience 154, 1132-1142. doi: 10.1016/j.neuroscience.2008.04.019 
Ivy, A. S., Rex, C. S., Chen, Y., Dubé, C, Maras, P. M., Grigoriadis, D. E., et al. (2010). Hippocampal dysfunction and cognitive impairments provoked by chronic earlylife stress involve excessive activation of CRH receptors. J. Neurosci. 30, 1300513015. doi: 10.1523/JNEUROSCI.1784-10.2010

Järlestedt, K., Naylor, A. S., Dean, J., Hagberg, H., and Mallard, C. (2013). Decreased survival of newborn neurons in the dorsal hippocampus after neonatal LPS exposure in mice. Neuroscience 253, 21-28. doi: 10.1016/j.neuroscience.2013.08.040

Jun, H., Mohammed Qasim Hussaini, S., Rigby, M. J., and Jang, M. H. (2012). Functional role of adult hippocampal neurogenesis as a therapeutic strategy for mental disorders. Neural Plast. 2012:854285. doi: 10.1155/2012/854285

Karakaş, P., Bozkir, M. G., Dere, F., Melik, E., Melik, E. B., Kaya, M., et al. (2009) The effects of maternal deprivation on the hippocampal structure in adult rats. Can. J. Neurol. Sci. 36, 356-362.

Kikusui, T., and Mori, Y. (2009). Behavioural and neurochemical consequences of early weaning in rodents. J. Neuroendocrinol. 21, 427-431. doi: 10.1111/j.1365 2826.2009.01837.x

King, R. S., DeBassio, W. A., Kemper, T. L., Rosene, D. L., Tonkiss, J., Galler, J. R., et al. (2004). Effects of prenatal protein malnutrition and acute postnatal stress on granule cell genesis in the fascia dentata of neonatal and juvenile rats. Brain Res. Dev. Brain Res. 150, 9-15. doi: 10.1016/j.devbrainres.2004.02.002

Kofman, O. (2002). The role of prenatal stress in the etiology of developmental behavioural disorders. Neurosci. Biobehav. Rev. 26, 457-470. doi:10.1016/S01497634(02)00015-5

Korosi, A., Naninck, E. F., Oomen, C. A., Schouten, M., Krugers, H., Fitzsimons, C., et al. (2012). Early-life stress mediated modulation of adult neurogenesis and behavior. Behav. Brain Res. 227, 400-409. doi: 10.1016/j.bbr.2011.07.037

Lajud, N., Gonzalez-Zapien, R., Roque, A., Tinajero, E., Valdez, J. J., Clapp, C., et al. (2013). Prolactin administration during early postnatal life decreases hippocampal and olfactory bulb neurogenesis and results in depressive-like behavior in adulthood. Horm. Behav. 64, 781-789. doi: 10.1016/j.yhbeh.2013.10.005

Lajud, N., Roque, A., Cajero, M., Gutierrez-Ospina, G., and Torner, L. (2012a). Periodic maternal separation decreases hippocampal neurogenesis without affecting basal corticosterone during the stress hyporesponsive period, but alters HPA axis and coping behavior in adulthood. Psychoneuroendocrinology 37, 410-420. doi: 10.1016/j.psyneuen.2011.07.011

Lajud, N., Roque, A., Junco, M., Meléndez, E., and Torner, L. (2012b). "Early effects of periodic maternal separation are reversed on adult female rats despite of gonadal hormones absence," in Proceedings of the FALAN First International Congress, Cancún.

Lee, J. H., Kim, H. J., Kim, J. G., Ryu, V., Kim, B. T., Kang, D. W., et al. (2007). Depressive behaviors and decreased expression of serotonin reuptake transporter in rats that experienced neonatal maternal separation. Neurosci. Res. 58, 32-39. doi: 10.1016/j.neures.2007.01.008

Lemaire, V., Koehl, M., Le, M. M., and Abrous, D. N. (2000). Prenatal stress produces learning deficits associated with an inhibition of neurogenesis in the hippocampus. Proc. Natl. Acad. Sci. U.S.A 97, 11032-11037. doi 10.1073/pnas.97.20.11032

Leslie, A. T., Akers, K. G., Krakowski, A. D., Stone, S. S., Sakaguchi, M., ArrudaCarvalho, M., et al. (2011). Impact of early adverse experience on complexity of adult-generated neurons. Transl. Psychiatry 1:e35. doi: 10.1038/tp.2011.38

Li, G., Kataoka, H., Coughlin, S. R., and Pleasure, S. J. (2009). Identification of a transient subpial neurogenic zone in the developing dentate gyrus and its regulation by Cxcl12 and reelin signaling. Development 136, 327-335. doi: 10.1242/dev.025742

Liao, X.-M, Yang, X. D., Jia, J., Li, J. T., Xie, X. M., Su, Y. A., et al. (2014). Blockade of corticotropin-releasing hormone receptor 1 attenuates early-life stress-induced synaptic abnormalities in the neonatal hippocampus. Hippocampus 24, 528-540. doi: 10.1002/hipo.22254

Loi, M., Koricka, S., Lucassen, P. J., and Joëls, M. (2014). Age- and sex-dependent effects of early life stress on hippocampal neurogenesis. Front. Endocrinol. 5:13. doi: 10.3389 /fendo. 2014.00013

Martin, L. A., Tan, S. S., and Goldowitz, D. (2002). Clonal architecture of the mouse hippocampus. J. Neurosci. 22, 3520-3530.

Mirescu, C., Peters, J. D., and Gould, E. (2004). Early life experience alters response of adult neurogenesis to stress. Nat. Neurosci. 7, 841-846. doi: 10.1038/nn1290

Musaelyan, K., Egeland, M., Fernandes, C., Pariante, C. M., Zunszain, P. A., and Thuret, S. (2014). Modulation of adult hippocampal neurogenesis by early-life environmental challenges triggering immune activation. Neural Plast. 2014:194396. doi: 10.1155/2014/194396
Naninck, E. F., Hoeijmakers, L., Kakava-Georgiadou, N., Meesters, A., Lazic, S. E., Lucassen, P. J., et al. (2014). Chronic early-life stress alters developmental and adult neurogenesis and impairs cognitive function in mice. Hippocampus. doi: 10.1002/hipo.22374 [Epub ahead of print].

Newport, D. J., Stowe, Z. N., and Nemeroff, C. B. (2002). Parental depression: animal models of an adverse life event. Am. J. Psychiatry 159, 1265-1283. doi: 10.1176/appi.ajp.159.8.1265

Nishi, M., Horii-Hayashi, N., and Sasagawa, T. (2014). Effects of early life adverse experiences on the brain: implications from maternal separation models in rodents. Front. Neurosci. 8:166. doi: 10.3389/fnins.2014.00166

Oomen, C. A., Girardi, C. E., Cahyadi, R., Verbeek, E. C., Krugers, H., Joëls, M., et al. (2009). Opposite effects of early maternal deprivation on neurogenesis in male versus female rats. PLoS ONE 4:e3675. doi: 10.1371/journal.pone.0 003675

Oomen, C. A., Soeters, H., Audureau, N., Vermunt, L., van Hasselt, F. N., and Manders, E. M. (2010). Severe early life stress hampers spatial learning and neurogenesis, but improves hippocampal synaptic plasticity and emotional learning under high stress conditions in adulthood. J. Neurosci. 30, 6635-6645. doi: 10.1523/JNEUROSCI.0247-10.2010

Oomen, C. A., Soeters, H., Audureau, N., Vermunt, L., van Hasselt, F. N., Manders, E. M., et al. (2011). Early maternal deprivation affects dentate gyrus structure and emotional learning in adult female rats. Psychopharmacology (Berl.) 214, 249-260. doi: 10.1007/s00213-010-19228

Oreland, S., Nylander, I., and Pickering, C. (2010). Prolonged maternal separation decreases granule cell number in the dentate gyrus of 3-week-old male rats. Int. J. Dev. Neurosci. 28, 139-144. doi: 10.1016/j.ijdevneu.2009.12.005

Petrik, D., Lagace, D. C., and Eisch, A. J. (2012). The neurogenesis hypothesis of affective and anxiety disorders: are we mistaking the scaffolding for the building? Neuropharmacology 62, 21-34. doi: 10.1016/j.neuropharm.2011.09.003

Plotsky, P. M., Thrivikraman, K. V., Nemeroff, C. B., Caldji, C., Sharma, S., and Meaney, M. J. (2005). Long-term consequences of neonatal rearing on central corticotropin-releasing factor systems in adult male rat offspring. Neuropsychopharmacology 30, 2192-2204. doi: 10.1038/sj.npp.1300769

Raceková, E., Lievajová, K., Danko, J., Martoncíková, M., Flesárová, S., Almasiová, V., et al. (2009). Maternal separation induced alterations of neurogenesis in the rat rostral migratory stream. Cell. Mol. Neurobiol. 29, 811-819. doi: 10.1007/s10571009-9362-x

Sanchez, M. M., Ladd, C. O., and Plotsky, P. M. (2001). Early adverse experience as a developmental risk factor for later psychopathology: evidence from rodent and primate models. Dev. Psychopathol. 13, 419-449. doi: $10.1017 /$ S0954579401003029

Santarelli, L., Saxe, M., Gross, C., Surget, A., Battaglia, F., Dulawa, S., et al. (2003). Requirement of hippocampal neurogenesis for the behavioral effects of antidepressants. Science 301, 805-809. doi: 10.1126/science.1083328

Sapolsky, R. M., and Meaney, M. J. (1986). Maturation of the adrenocortical stress response: neuroendocrine control mechanisms and the stress hyporesponsive period. Brain Res. 396, 64-76. doi: 10.1016/0165-0173(86)90010-X

Schlessinger, A. R., Cowan, W. M., and Gottlieb, D. I. (1975). An autoradiographic study of the time of origin and the pattern of granule cell migration in the dentate gyrus of the rat. J. Comp. Neurol. 159, 149-175. doi: 10.1002/cne.901 590202

Schmidt, M. V., Sterlemann, V., Wagner, K., Niederleitner, B., Ganea, K., Liebl, C., et al. (2009). Postnatal glucocorticoid excess due to pituitary glucocorticoid receptor deficiency: differential short- and long-term consequences. Endocrinology 150, 2709-2716. doi: 10.1210/en.2008-1211

Shingo, T., Gregg, C., Enwere, E., Fujikawa, H., Hassam, R., Geary, C., et al. (2003). Pregnancy-stimulated neurogenesis in the adult female forebrain mediated by prolactin. Science 299, 117-120. doi: 10.1126/science.1076647

Suchecki, D., Mozaffarian, D., Gross, G., Rosenfeld, P., and Levine, S. (1993). Effects of maternal deprivation on the ACTH stress response in the infant rat. Neuroendocrinology 57, 204-212. doi: 10.1159/000126361

Suri, D., Veenit, V., Sarkar, A., Thiagarajan, D., Kumar, A., Nestler, E. J., et al. (2013). Early stress evokes age-dependent biphasic changes in hippocampal neurogenesis, BDNF expression, and cognition. Biol. Psychiatry 73, 658-666. doi: 10.1016/j.biopsych.2012.10.023

Tanapat, P., Galea, L. A., and Gould, E. (1998). Stress inhibits the proliferation of granule cell precursors in the developing dentate gyrus. Int. J. Dev. Neurosci. 16, 235-239. doi: 10.1016/S0736-5748(98)00029-X 
Torner, L., Karg, S., Blume, A., Kandasamy, M., Kuhn, H. G., Winkler, J., et al. (2009). Prolactin prevents chronic stress-induced decrease of adult hippocampal neurogenesis and promotes neuronal fate. J. Neurosci. 29, 1826-1833. doi: 10.1523/JNEUROSCI.3178-08.2009

Torner, L., Toschi, N., Pohlinger, A., Landgraf, R., and Neumann, I. D., (2001) Anxiolytic and anti-stress effects of brain prolactin: improved efficacy of antisense targeting of the prolactin receptor by molecular modeling. J. Neurosci. 21, 32073214.

Tsuda, M. C., and Ogawa, S. (2012). Long-lasting consequences of neonatal maternal separation on social behaviors in ovariectomized female mice. PLoS ONE 7:e33028. doi: 10.1371/journal.pone.0033028

Vega, C., Moreno-Carranza, B., Zamorano, M., Quintanar-Stephano, A., Mendez, I., Thebault, S., et al. (2010). Prolactin promotes oxytocin and vasopressin release by activating neuronal nitric oxide synthase in the supraoptic and paraventricular nuclei. Am. J. Physiol. Regul. Integr. Comp. Physiol. 299, R1701-R1708. doi: 10.1152/ajpregu.00575.2010

Walsh, R. J., Slaby, F. J., and Posner, B. I., (1987). A receptor-mediated mechanism for the transport of prolactin from blood to cerebrospinal fluid. Endocrinology 120, 1846-1850. doi: 10.1210/endo-120-5-1846

Wang, A., Nie, W., Li, H., Hou, Y., Yu, Z., Fan, Q., et al. (2014). Epigenetic upregulation of corticotropin-releasing hormone mediates postnatal maternal separation-induced memory deficiency. PLoS ONE 9:e94394. doi: 10.1371/journal.pone.0094394

Wang, H., and Gondré-Lewis, M. C. (2013). Prenatal nicotine and maternal deprivation stress de-regulate the development of CA1, CA3, and dentate gyrus neurons in hippocampus of infant rats. PLOS ONE 8:e65517. doi: 10.1371/journal.pone.0065517

Wang, X. D., Labermaier, C., Holsboer, F., Wurst, W., Deussing, J. M., Müller, M. B., et al. (2012). Early-life stress-induced anxiety-related behavior in adult mice partially requires forebrain corticotropin-releasing hormone receptor 1. Eur. J. Neurosci. 36, 2360-2367. doi: 10.1111/j.1460-9568.2012.08148.x
Yi, S. J., and Baram, T. Z. (1994). Corticotropin-releasing hormone mediates the response to cold stress in the neonatal rat without compensatory enhancement of the peptide's gene expression. Endocrinology 135, 2364-2368.

Zamorano, M., Ledesma-Colunga, M. G., Adán, N., Vera-Massieu, C., Lemini, M., Méndez, I., et al. (2014). Prolactin-derived vasoinhibins increase anxietyand depression-related behaviors. Psychoneuroendocrinology 44, 123-132. doi: 10.1016/j.psyneuen.2014.03.006

Zhang, J. M., Konkle, A. T., Zup, S. L., and McCarthy, M. M. (2008). Impact of sex and hormones on new cells in the developing rat hippocampus: a novel source of sex dimorphism? Eur. J Neurosci. 27, 791-800. doi: 10.1111/j.14609568.2008.06073.x

Zhang, K., Xu, H., Cao, L., Li, K., and Huang, Q. (2013). Interleukin-1 $\beta$ inhibits the differentiation of hippocampal neural precursor cells into serotonergic neurons. Brain Res. 1490, 193-201. doi: 10.1016/j.brainres.2012.10.025

Conflict of Interest Statement: The authors declare that the research was conducted in the absence of any commercial or financial relationships that could be construed as a potential conflict of interest.

Received: 29 October 2014; accepted: 15 January 2015; published online: 13 February 2015.

Citation: Lajud N and Torner L (2015) Early life stress and hippocampal neurogenesis in the neonate: sexual dimorphism, long term consequences and possible mediators. Front. Mol. Neurosci. 8:3. doi: 10.3389/fnmol.2015.00003

This article was submitted to the journal Frontiers in Molecular Neuroscience. Copyright (C) 2015 Lajud and Torner. This is an open-access article distributed under the terms of the Creative Commons Attribution License (CC BY). The use, distribution or reproduction in other forums is permitted, provided the original author(s) or licensor are credited and that the original publication in this journal is cited, in accordance with accepted academic practice. No use, distribution or reproduction is permitted which does not comply with these terms. 